\title{
Investigating the consumption anxiety thesis: aesthetic choice, narrativisation and social performance
}

\author{
Dr Ian Woodward \\ School of Arts \\ Griffith University
}

\begin{abstract}
Warde's (1994) theoretical analysis of possible anxieties provoked in the act of consumption synthesises a large body of contemporary literature on uncertainty, social change and consumption. In doing so, it offers a predominantly structural model of the anxiety provoking tensions and forces individual consumers may be exposed to. Drawing on the work of contemporary figurehead theorists of social change, and proposing his own application of Durkheim's model of suicide to the problem of consumption anxiety, Warde presents a model of how anxieties and their mitigation are embedded within configurations of contemporary consumer culture. Though Warde's analysis illustrates the structural, theoretical context of potential consumption anxieties for particular social groups, it is unable to specify how such anxieties are manifested and managed - or performed - by individuals within specific social and consumption settings. This paper takes an interpretive approach, conceptualising consumption anxiety as a discursive, narrative phenomenon likely to surface within particular social settings that are conducive to generating expressions of anxiety. The paper also considers the relation between narrativisation and objects, arguing that the cultural capacity of objects must be understood within local settings where objects are afforded a capacity to act through various discourses. The argument is drawn using selections of face-to-face interview data collected from a sample of middle-class householders on the practice of home decoration.
\end{abstract}




\section{Investigating the consumption anxiety thesis: aesthetic choice, narrativisation and social performance}

\section{Introduction}

This paper applies an interpretive methodology to excerpts from interview data to explore a specific proposition in consumption studies: that under conditions of increased consumer choice within the arena of aesthetic consumption ${ }^{1}$, selection can become a socially and personally risky activity that provokes anxiety within some consumers. In the domain of consumption studies the thesis - notably discussed and critically analysed in Warde's (1994) important paper - echoes, applies and specifies major themes in recent literatures on macro-social change that illustrate what Bauman (1987) has diagnosed as the proliferation of interpretations, and the paucity of legislators. Despite the intellectual appeal and novelty of the anxiety thesis, and the potential importance of the idea of anxiety within consumption studies, there has been no subsequent development of Warde's discussion. This paper is less a test, than a further exploration of the consumption anxiety thesis using an idiographic approach. Its empirical generalisability is restricted, but suggestive of important paths to follow in the study of consumption anxiety.

On a more ambitious theoretical plane the paper also proposes an agenda to strengthen the consumption studies program through application of a performance studies approach. The performance paradigm, which I précis later in this introduction, can be distinguished from two dominant theoretical skeins in consumption studies. The first is the study of consumption and aesthetic taste through describing the social distributions and homologies of consumption, inspired largely by Bourdieu (1984). Bourdieu's research has motivated a range of important inquiry into the conditions of cultural production and consumption within various fields ${ }^{2}$, but its dominance has meant less attention has been given to problems of subjectivity, and the accomplishment of taste repertoires and practices using qualitative, interpretive frameworks. Questions of social location and symbolic power do need recognition, but need not be reduced to the usual sociological ciphers and techniques ${ }^{3}$. If we understand aesthetic consumption as driven by the need to establish cultural identities and affiliations, then conceptualising it as a type of 'consumption performance' where actors harness symbolic codes, narratives and objects to achieve certain ends, can offer new paths for conceptualising consumption. Indeed, the underdeveloped - though seductive - component of Bourdieu's well known study of aesthetic taste is the idea that social agents enact cultural knowledges to achieve strategic ends, an idea which seems to have affinities with performance theory. Bourdieu argues such enactments accrue 
various sorts of capital and play a part in social reproduction. He is less interested in questions of meaning, action and the work of symbolic manipulation. By focussing on the interplay of individual enactment of consumption and the symbolic codes that such performances are drawn from, the limiting dominant tendency within postmodern accounts to see consumption as something which is highly individualised, playful, boundary-less and distinction seeking is also by-passed.

Recent developments in performance theory have emerged from a range of theoretical traditions. Goffman (1959) used the concept of performance to explain the enactment of social roles according to the logic of status management. More recent developments in performance theory (Geertz 1973, Turner 1982, Schechner 1993, Butler 1997, Alexander 2004a, 2004b) seek to understand the performative character of identity by drawing upon theoretical resources of symbolic action, ritual and social drama to show how social action is contingent upon history and collective sentiments, but must be brought into existence by continuous performative acts which actualise and reproduce the identities of social actors (Butler 1997:409). In his exposition of the elements of performance Alexander (2004b:529) defines cultural performance as:

the social process by which actors, individually or in concert, display for others the meaning of the social situation. This meaning may or may not be one to which they themselves consciously adhere; it is the meaning that they, as social actors, consciously or unconsciously wish to have others believe. In order for their display to be effective, actors must offer a plausible performance, one that leads those to whom their actions and gestures are directed to accept their motives and explanations as a reasonable account.

The paper considers how the idea of cultural performance could be fruitfully applied within the field of consumption studies. It argues the way consumer objects acquire their cultural meaning is within local settings, where participants confer consumption objects a social life through offering active, creative accounts, or narratives. Such narratives are locally accomplished phenomena, existing within various social settings - including the research interview which is the setting of the current research - where individuals are called to offer a believable, convincing, or 'fused' (Alexander 2004a) account of their relations with consumer objects ${ }^{4}$.

Warde (1994) points out that consumption choices can possibly be problematic, risky or anxiety provoking, though this will depend on social context, the relative cultural authority of the person who is selecting and consuming the good, and the degree of importance they invest in their own, and others' perception of, personal consumption choices. The purpose of Warde's analysis is to 
offer a theoretical model of the social-structural processes and forces that may shape potentially risky consumption selections. This paper argues for an alternative, but complementary, approach to the problem by conceptualising consumption anxiety as an emotion experienced by actors in the context of particular social settings where presentations of self are called to account - where there must be a performative confluence between 'things' (objects of consumption) and 'words' (narratives of aesthetic judgement) ${ }^{5}$. The face-to-face research interview, which is the research strategy used in this paper, is one such setting where the need to justify and explain one's actions, selections or behaviours is especially acute, calling for 'performative fusion' (Alexander 2004a). Using excerpts from face-to-face interview data collected from a sample of middle-class householders on the practice of home decoration, this paper argues that an important way consumption anxieties arise is when individuals are called to give a 'warrantable' account (Denzin 1989) of their consumption choices. While such accounts are considered in this paper through the social setting of the face-to-face research interview, accounts and justifications are also routinely given to others in a range of everyday situations.

According to Warde's (1994) interpetation, anxiety - and its management - is the product of structural locations and social forces. The argument pursued here is that it is only in the space of social performance that anxiety can surface, whereby an actor's credibility, believability or veracity comes into question. For a narrative to be culturally warrantable it must be able to be told and heard as 'true' by participants in a social exchange. That is, there must be an aesthetic 'fusion' between the material and discursive, articulation and reception: "a coming together of background meaning, actors, props, scripts, direction and audience” where performances are experienced as convincing or authentic by participants (Alexander 2004a:92). It is in the process of providing such warrantable accounts of one's aesthetic choices that anxieties or uncertainties about one's performative mastery of 'scripts' (narratives) and 'props' (objects) can surface. As Alexander (2004) points out, lurking alongside any performance is contingency and openendedness, where scripts or narratives can breakdown, or go awry. This is all too true in the field of everyday aesthetics (e.g. home decoration), where the concepts and language required to express judgements are the products of sustained, intricate cultural learning. In the context of this paper, awareness that aesthetic selection and organisation can be a socially risky process that requires justification, especially in the context of the research interview methodology used in this paper, means that uncertainties and anxieties over one's choices can be expressed as part of the narrativisation of selection. Such narratives are an important part of the process of consumption, which should be seen to continue after objects have been purchased (Miller 1987), because they 
involve interpretations which serve to de-commodify and give subjective meaning to one's possessions (Kopytoff 1986) - translating them from things into words, material objects into meanings.

\section{Defining anxiety}

I turn firstly to define anxiety, its constituent dimensions, and its psychosocial bases. In his seminal review of modern theories of anxiety, Rollo May (1950:190) points out that it is commonplace for psychological accounts to begin by distinguishing anxiety from fear. Giddens' (1991:43) analysis follows a similar path, which is acknowledged to be indebted to Freud (1922). According to this model, fear is based on the expectancy of a specific threat to a person. The threat may be physical or psychological in nature but, importantly, the threat is specific and known to the person. Thus, one has a fear. Alternately, anxiety is understood to be a diffuse emotion - one is anxious. As Freud demarcates: "I think that anxiety is used in connection with a condition regardless of any objective, while fear is essentially directed toward an object" (Freud 1922:342). Anxiety is seen to be diffuse or 'objectless' because it does not threaten the physical body or involve a specific, containable episode of threat. Indeed, it is objectless precisely because it strikes neither concrete nor physical things, but rather the essence of a person's identity. For this reason, it is an intense threat to the emotional security pattern of self that fear does not immediately contain.

Anxiety is also seen to have a metaphysical dimension whereby such threats challenge the inherent stability and value of one's perception of self. Thus, Kierkegaard defines anxiety as the “fear of nothingness" (May 1950:193). In The Concept of Dread Kierkegaard (1957) understands the human condition as defined by the dynamic between freedom and anxiety. Freedom, understood abstractly as 'possibility', affords people self-awareness, and in turn, can produce anxiety about the suitability of different courses of action (May 1950:32). Anxiety is thus inextricably linked to autonomous selfhood. In contemporary parlance, it is the condition of 'reflexivity of the self' that provides the structural context for the possibility of anxiety. What is at stake is the integrity of self-identity which must be maintained in the face of the tribulations and trails of late modern life (Giddens 1991). It is May's definition of anxiety, formulated over half a century ago, that the psychological and social bases of the condition are highlighted most precisely, situating the protection of identity as central to the experience of anxiety: 
"Anxiety is the apprehension cued off by a threat to some value which the individual holds essential to his existence as a personality” (May 1950:191)

In this paper I understand anxiety, after May (1950), to be a feeling cued by a perceived threat to the stability or 'warrantability' (Denzin 1989) of a person's account and justification of their behaviours or choices. Thus, anxiety can be triggered if an individual believes that others may question or negatively evaluate their aesthetic selections or choice. This essentially involves a challenge to the integrity of an account, in turn bringing the warrantability of their narrative into question. Leary (1983) gives a similar definition and makes a useful distinction between psychological and clinical anxieties, and social anxieties. He understands the quality of 'evaluation' to be crucial to manifestations of social anxiety, so that social anxiety occurs when one fears making an unfavourable impression upon others, suffering consequent negative evaluation. Leary clarifies that social anxiety is: "anxiety resulting from the prospect or presence of interpersonal evaluation in real or imagined social settings” (1983:14). Such a definition makes it apparent that in the arena of aesthetic consumption when presentations are called to account in social settings, it is possible for some people to experience social anxiety as a result of their choices.

Having defined social anxiety, the question arises: how can it be recognized and studied? Within clinical psychology the process is assisted by existence of standardised baseline assessment instruments that measure degrees of anxiety and its dimensions. For sociologists these instruments are most likely viewed as problematic, yet within their home disciplines they serve to definitively identify various types and degrees of anxiety ${ }^{6}$. As for sociological studies of anxiety, especially those using methodologies that follow conventions of the semi-structured interview, identification of social anxiety is somewhat more difficult. Following Leary's review of social anxiety research (1983:99), I make the following suggestion about the precursors and dimensions of social anxiety which can assist in its identification. First, we can say that a person is more likely to experience social anxiety in the following settings or situations: (i) when dealing with strangers or people who one has minimal information about (especially in non-routine settings), (ii) when dealing with situations or roles that they have not previously occupied, (iii) when dealing with others in authority or in higher status positions, and (iv) when one is in an unstructured social setting where what is 'expected' is not immediately clear to the participant. Next, I propose that we can recognise social anxiety - or attempts to ease or overcome such anxieties - in any of the following events, including: (i) when a participant in an interaction 
engage in conversational repair to neutralise errors or potential embarrassments, (ii) when a person self-monitors by making a contrary qualification to an account to avoid the risk of negative appraisal, (iii) when an individual offers an advance disclaimer with an account, and (iv) when an individual contrasts their current situation with a more desirable situation for the purpose of conveying awareness of things that may be perceived as less than ideal.

\section{Anxiety: from structure to situation}

Given Warde's (1994) model of consumption anxiety, and the contingent model of social anxiety proposed in this paper, we can delineate two broad ways to conceptualise the origin of consumption anxiety. The first is a structural conceptualization, which posits that consumption anxiety is directed by the broader social and cultural conditions which underpin consumption choices. An alternative possibility, which is pursued in this paper, is that anxiety surfaces within local situational contexts and is experienced by individuals as they seek to produce fused accounts and justifications (Alexander 2004a) of their material choices for others in the context of social interactions. We can understand this latter conceptualisation as a performance model of consumption anxiety. In the section that follows I briefly elaborate these two models.

First, to the structural model of consumption anxiety. The theoretical groundwork for this model is likely well known to most readers, as articulated in the work of Bauman, Beck and Giddens (and Warde's 1994 summary of their work), and I therefore offer a succinct restatement of the position. Structural accounts embed anxiety within larger discourses on the existence of uncertainties in the contemporary era and highlight the ways anxiety and larger contexts such as risk, uncertainty and threat have been a dominant thread in recent theories of social change (Wilkinson 1999). For the structural model of consumption anxiety, the institutional reasons for such feelings of doubt and uncertainty are fundamentally congruous, resting on a thesis concerning the dissolution of the importance of traditional institutional influence on cultural life and an associated intensification in the importance of individual responsibility and biography. Within the domain of aesthetic consumption, it is easy to identify how such tendencies could come to be played out - consumption choices, styles and possible tastes have multiplied exponentially and change their characteristics and meanings rapidly; individuals increasingly engage with consumption goods as a way of constructing and managing identity; and on the face of it, there are few authorities to consult about such choices that can be seen by individuals, after all, as matters of individual taste. In this context it is worth revisiting Bauman's pithy observation on the dilemma associated with freedom in postmodernity as it captures perfectly the 
uncertainties individuals may face - "It means the exhilarating freedom to pursue anything and the mind-boggling uncertainty as to what is worth pursuing and in the name of what one should pursue it” (Bauman 1992:vii).

In his application of these ideas to the domain of consumption, Warde (1994) also identifies that consumption anxiety is the manifestation of two interrelated theoretical processes - increased choice, and the diminished role of authority in social relations. Warde's conclusion, which is theorised through a deft appropriation of the Durkheimian typology of suicide, is that for those who are predisposed to experience anxiety adequate 'insurance' is generally found by investments in specialist bodies of knowledge which assist in dampening perceptions of danger and providing expert justifications for aesthetic choice: for example, advertising, peer groups, and magazines. On the other hand, there are those - the 'anomic egoists' - who feel no such anxieties, are relatively disengaged from the game of status and identity-driven consumption, and are seen to have little personal interest invested in their choices. In a more recent reflection, Warde (1997) has considered the question of consumption anxiety without resolution. He takes a empiricist position by expressing some skepticism over Bauman's view on the extent to which anxiety can be seen to be relevant to consumption. He raises a series of pertinent questions about the 'epidemiology' of such anxiety. Is 'anxiety' the most accurate concept to apply when there are few, if any, studies of such anxieties available? Is anxiety present in all consumption decisions, and is such consumption anxiety time-space contingent, and in turn dependent upon class, age or gender? Furthermore, as Warde points out, wouldn't informalisation and individualisation processes reduce "the likelihood of embarrassment arising from improper adornment”? (Warde 1994:894) Yet, despite such questions, reflection by Warde suggests he remains attracted to the anxiety thesis, and he acknowledges that consumer "selection becomes a risky, unregulated and uncertain exercise of freedom” (Warde 1997:11).

The question of consumption anxiety and whether it is attributable to class location, social structural factors which contextualise the environment of selection, or situational factors, stands as an interesting problem for further investigation. While this paper cannot be seen as a definitive test of such alternative explanations, it takes up the case for a performance based account of consumption anxiety that proposes consumption anxieties surface within the context of accounting behaviours related to the narrativisation of aesthetic choices - where actors seek to achieve a fusion or confluence between words and object things. In the context of giving such accounts to others - in this case the interviewer - social anxiety can manifest in a variety of 
typical contexts, but generally as a result of a person feeling their account is likely to be received negatively by an audience. This realisation causes them to question their narrative account, which in turn brings into play a particular strategy to ease feelings of anxiety (see discussion of precursors and dimensions of anxiety, above). This paper focuses on the way consumers justify or account for their choices well after the act of purchase, the stage labeled 'singularisation' by Kopytoff (1986). Within the context of the face-to-face interview in the process of accounting for home decoration selections interviewees manifest two specific types of anxieties which I propose as preliminary distinctions useful for further inquiry into consumption anxiety. These types of anxiety are labeled 'status anxiety' and 'identity anxiety'. The meaning of each is explored in the interview excerpts that follow the methodological discussion.

\section{Methodology}

Following a mail-out to selected streets within City X, face-to-face interviews were carried out with twenty-four householders in two suburbs, for the purposes of this paper called 'A' and 'B'. Suburb A is one of the city Xs 'establishment' suburbs, and borders other prestigious areas within the city. The streets of Suburb A that I selected are in an area some real estate agents refer to as 'Suburb A Heights', because of its prominent location on the edge of a cliff overlooking an expansive reach of the City X River. The area has some of the city's largest colonial houses, but has also been a suburb where moneyed gentrifiers purchase highly valued land with perceived unfashionable or modestly constructed mid-century houses, then demolish them to construct new dwellings. Some of these new dwellings are architecturally valuable, while others are merely massive and opulent. While Suburb A represents an area of extreme wealth and has a unique location to attract the moneyed and elite of the city, Suburb B is an archetypal example of an inner-city suburb that has been subject to gentrification processes over the last couple of decades. Suburb B's houses are generally smaller and less impressive colonial styles, though this depends on location and especially elevation, and most residences could be classified as colonial cottages in contrast to Suburb A's sprawling colonial mansions. However, the inner-city location and the fashionability of the colonial style have attracted young, mostly professional people to the area who renovate the houses and hope to benefit from significant capital gains. The interviewees in the sample come from a range of age groups, but are relatively homogeneous in that they are generally university educated, most have household incomes above $\$ 80000$, and most own their home. Notably, most respondents were women. The interviews lasted 75-90 minutes and were tape-recorded, then transcribed. The inductive principles of open coding were used in the analysis of interview data (Glaser and Strauss 1967; Strauss and Corbin 1990). 
The interviews began with an informal tour of the house and its contents. In exploring the home as a site for the practice of aesthetic judgement, the idea of 'taste' was not explicitly put to interviewees as the chief concern of the research. Rather, my decision was to leave the topic for investigation relatively open, and state generally to the respondent that my interest was 'the way people decorate their homes, the reasons they make such choices and the things that have influenced the way they have decorated their homes'. The advantage of this approach is that respondents do end up talking about their tastes, however, the semi-structured approach lets them decide what aspects of domestic material culture to choose in order to construct their account. The talk of respondents, and the material culture it is associated with, thus becomes evidence of their understandings of taste. Indeed, the objects they choose to discuss are the physical manifestation of such discursive understandings. After the tour a semi-structured interview took place and was a further opportunity to attend to points of interest and clarification, and to put to interviewees hypotheses developed in previous interviews. It is important to note therefore, that this was not a study that specifically sought to investigate consumption anxiety. Rather, anxieties surfaced in the context of interviews as a routine part of some respondent's accounts of their home decoration practice. In this sense these data are accidentally created as a result of the data collection methodology. Anxieties did not, therefore, dominate the tenor of the interviews that are the source of these data, but are transient features within them ${ }^{7}$.

\section{Expressions of anxiety and home decoration}

My interpretation of the interview excerpts following is that these enthusiastic, committed consumers were anxious not only about making what were perceived to be aesthetically superior choices, they were also anxious to present an identity that is independent or free from a consumer status. For these respondents, acting as a consumer with good taste is thus perceived to be about engaging with the latest, most fashionable or high-status commodities, styles and fashions in a way that is not perceived to be too enthusiastic, gauche or lacking in refinement. Essentially, one could summarise this trade-off by saying it is about a seeking a balance between commodification and authenticity (Giddens 1991). These dual discourses of self-presentation were evident throughout the cases I report here, and on occasions were prominent when presented mutually.

For those who I have identified as the most enthusiastic consumers there is an apparent statusbased anxiety relating to possessing a domestic environment that is ordered, non-polluted, and above all, fits a person's criteria for being aesthetically pleasing. Anxiety can arise when one - 
presumably the interviewee - feels that others may perceive their aesthetic choices as inferior or aesthetically problematic on some way. Take the case of Anna and the 'boy's TV'. As Anna tours me through her house we reach the lounge room. She begins by advancing a justification to account for what she believes may be perceived as an extravagantly large television set:

Anna: “There's four kids in our family, two of them are at home and they're both males, so I live with three males, so I'm outnumbered with decisions like the TV

Int.: What do you mean?

Anna: That it's too large and it's ugly and I don’t really want it in the living area

Int.: Why not? Could you explain...?

Anna: Because it's large and ugly and intrusive and doesn't fit in with what I see as the function, purpose and nature of the living room which is a place to sit and relax and read, not watch TV”

The performative capacity of the television is apparent. It is criticised for its aesthetic qualities ugliness, intrusiveness and poor aesthetic integration. However, Anna's objection to the television set is also based upon the way its compromises the ideal of family life, which to her should preferably involve having a lounge room that is relaxing and homely. By moving to highlight aesthetic and symbolic problems with the television set without the prompting of the interviewer, Anna provides a type of advance disclaimer to the audience to signal her anxiety about the object.

In another household, Helen admits to feeling uncomfortable with aspects of her homes' colour scheme, and is an issue she has returned to throughout her home renovation. Her anxiety concerns the presentation of an integrated, sympathetic colour scheme for her couch and cushions. Even though she uses an interior designer to assist her aesthetic choices, Helen is anxious about the colour selections. Helen's narrativisation of her aesthetic dilemma may be designed to save face within the interactional setting. By prior highlighting of problems one overcomes the potential embarrassment of someone else pointing them out:

"the interior designer I talked with talked me into getting a bit of Designer's Guild, this colour. Originally, we agreed on blue, I've got one cushion left and that's going back. The reason she suggested I use the bright colours, which I can see what she's saying, was to link up with this Designer's Guild feature in the wallpaper, which is fine. I just don't think there's enough colour in there to warrant picking it up and I just wasn't comfortable with it" 
Employing an interior decorator as an aesthetic expert is the obvious solution to the problem of this form of anxiety: when choices are unclear and there is potential to make incorrect choices, one places substantial trust in aesthetic experts. For Helen this involved shopping around for a reliable interior decorator:

“...Pretty much I do it with the interior designer. Although, definitely I wouldn't say that I'd use her all the time. I think she's been good but when it came to out here though there's another interior designer I might use because I just ... I couldn't afford to stuff up out here. And the girl I use, as much as I like her I just don't think she's got the experience and the woman who I would probably use has done my mother's house and has also helped me with a few things, I got her in to help me with colours, in terms of the exterior of the house and also to help me do the kitchen and dining and the colours for the bathroom. She's just so good and she's just done my mother's lounge area and she's done Mum's whole house and Mum's house is amazing, she just never gets it wrong, she really doesn't. She's just very, very, very good.”

There are a couple of interesting expressions to consider here. The first is Helen's assertion that "I couldn't afford to stuff up here". I do not believe that Helen was referring to the monetary costs of "stuffing up" the decoration of her living area, though I don't deny that this could have been of some significance to her. Rather, I think the more important aspect is fear of having a redecorated lounge room that she perceives as aesthetically dubious. Helen refers to her mother's decorator, who "never gets it wrong". The issue at hand is one of fear of styles and aesthetic forms that one perceives somehow diminish one's status in the universe of tastes. It is fear of aesthetic pollution, of bringing something into one's house that may be perceived by important others to be outside the boundaries of one's taste "symmetries and correspondences" (Bourdieu 1984:174). For Helen - someone who spends much time thinking about her aesthetic selections the matter of the colour scheme and the way to render a satisfying combination of colours is a source of social anxiety manifested in the company of the interviewer. Another notable aspect is the way Helen refers to the inexperienced 'girl' decorator who presents potential risks compared to the "woman who has ... done my mother's house". Elsewhere in the interview, Helen employs the same age-based status signifier when she revisits this problem:

“... and I think that's where someone like Mary would know me well enough or pick up on my tastes. Whereas, the other lass, she's gorgeous, but she was probably a bit inexperienced in that she didn't detect that 'hang on, maybe this isn't you', you're not going to like this down the track'” 
In another case, Marie also uses an interior decorator for ideas and access to specialist resources, making it clear her concern to decorate skilfully and to avoid the significant monetary costs of decoration errors:

“And I've also made sure that I've had an interior decorator ... not only that she's given me ideas but you can't buy the things anymore in ordinary outlets so you've actually got to combine an interior decorator. And that's what I liked about this particular lass, she came to see me and she didn't try to make it into her house...I think it's nice to have someone else to bounce it off particularly when interior decorating is a very expensive exercise and you don't want to make mistakes”.

Again, Marie's response exhibits an anxiety over somehow getting matters of taste wrong - of decorating without the help of an aesthetic expert and not ending up with a pleasing result. Marie's anxiety to achieve an aesthetic confluence of colour, material and object is partly assuaged - and no doubt also partly generated - by dreaming based on reading decorator magazines. Such resources are relatively inexpensive ways of acquiring aesthetic expertise that also serve to generate dreams of new and better aesthetic styles and objects. Presumably, the pleasure derived comes from using media representations to construct imaginative scenarios (Campbell 1987, 1994) about what one's house and garden might ideally be like. It is here that the nexus between production and consumption of consumer desire become most apparent:

“It's actually produced in Spain but it's mainly an English magazine. It's just about all the rich and famous but it has beautiful homesteads in it, beautiful homesteads. There's always an article, see here's one here, there is always an article on someone and their home ... There's a beautiful photo here that I want to show you, I think it's of Prince Charles Highgrove - his gardens. You just pan over the page - it’s just brilliant”

In a nearby street in the same suburb as Marie, Julie is also anxious about being able to live her life surrounded by "beautiful things". These things, when arranged tastefully within her home environment, add up to something that is deeply satisfying, perhaps even uplifting or edifying: "the whole thing you know, not just the thing on its own, you put them together and they complement each other and they look gorgeous so it's a union of lifestyle and pretty things”. Both Julie, and another respondent Cath, enjoy looking at things they perceive to be beautiful, perhaps acquiring them, but more importantly, dreaming of what they might offer:

"Int.: Where do you get the ideas for decorating your home from?

Cath: I don't know really ... it's something I've always enjoyed. I guess I read magazines, I love shopping. I could spend an afternoon just pottering around 
Freedom or somewhere like that, not with the intention of buying anything, but just because I like looking at what other people do and their ideas";

Int.: You said that you loved having beautiful things and displaying them. What makes you feel good about that?

Julie: I enjoy beautiful things whether it be in my home, going to the ballet, seeing someone sing a beautiful song, whatever. And I think bearing all that in mind I mean really who wants to sit and look at something that's really ugly and not attractive to the eye, and I hope you don't think this sounds completely shallow or anything, but I like to be surrounded by beautiful things”.

Apart from this aesthetic anxiety over matters of decoration and the possession of beautiful objects, there are also anxieties about counter-balancing the search for further dreamings about commodity objects. These preliminary data therefore suggest that consumption anxiety seems to exist in two basic types. To recap the empirical argument, there exists a level of aesthetic anxiety, over such things as whether one has chosen the right colour, or whether one has selected a competent interior decorator. But there is also reflexivity amongst these enthusiastic consumers which suggests a degree of skepticism, or at least questioning, regarding the extent of their own consumption activities. Whilst they seem to wholeheartedly endorse consumerism through their practices, there is an apparent fear that one's identity may be perceived as shallow by an overemphasis on the pursuit of, or dreaming about, commodities that are perceived to be aesthetically excellent. This can be seen as a way of qualifying their account - of providing a balance between their practices of acquisitiveness and the desire for 'decommodified authenticity' - for the interviewer. Consider the case of Anna once again. She lives in an impressive colonial house and has recently completed a substantial kitchen renovation. Part of the renovation involved the acquisition of a large, expensive European oven. Essentially, Anna struggles with the question of what buying the oven makes her, or might suggest about her. Her anxiety is not over aesthetics she is very pleased with the impressive oven the adorns her kitchen. Rather, her concern is with how she is to reconcile her materialist desires with aspects of her self.

“Anna: It's almost kind of like an art piece because usually you see it coming through that open space, and it fits in with the house, and I guess it says something fairly traditional, not necessarily that I espouse those ideals completely

Int.: What message does it send?

Anna: Well, I guess it says something about the relationship of food and household, and that's involved in nurturing ... It's just really if I spend that there's a pressure to, 
you know, and I don't see myself as someone traditional who spends a lot of the time cooking every night”

Later in the interview Anna makes it clear to me that she is not to be read as someone obsessed with the acquisition and display of status goods. Anna maintains that while things are aesthetically pleasing are satisfying to her this is not the sum of her identity:

"I mean I probably will put in more pieces like lampshades that actually match with the fabric, so there is some sense of coordinated colour that's aesthetically pleasing to the eye, so I can appreciate them when its done, but I can live with not having it as well, or having them to a lesser extent.... I actually have sense of not being so attached to objects that they rule my life, they're something that, you know, are transient and come and go, that I can appreciate in that period of time, but they don't have a power over me"

Likewise, Cath says that "while I like things to look good quality and appropriate to the setting and I guess fairly up-to-date, I wouldn't say that I'm dictated by it”, and Julie states simply while we tour her house - "I hope you don't think this sounds completely shallow or anything but I like to be surrounded by beautiful things". For those who participate thoroughly in consumption and the fickle aesthetics of fashions, there is an anxiety over their extent of participation, and a realisation that the desire to accumulate things shouldn't go unchecked.

For those who are less enthusiastic and anxious about their aesthetic consumption, questions of personal identity seem less tied to patterns of consumption and more to the creation of an identity free of the need to accumulate commodities. These people cannot - or do not - avoid engagement with the market of goods and the trends of fashion, however they strive to maintain a distance, at least in the way they account for their own behaviour. For example, Marg admits that occasionally “in dentist's waiting rooms and stuff, I’ve looked at magazines and lusted after neat little tables with lovely table clothes... and I thought 'oh yeah, I should have all these things, these nice things'...but I'm not a slave to fashion”. Christina is openly hostile to decoration and fashion, and claims to be "totally disinterested in décor", and is dismissive of those who like to spend time browsing in furniture stores: "going to Freedom Furniture or something like that on a Sunday, just for something to do...nup...I just think that's so funny”. Here, the interviewees are anxious to present to the interviewer an authentic identity that cannot be interpreted as overdetermined by one’s consumer status. 


\section{$\underline{\text { Discussion }}$}

Bataille (1985) wrote that the condition of abundance is crucial to interpreting capitalism. One way of reflecting upon the questions considered in this paper is to contextualise them in terms of the concept of abundance, for a profusion of consumer possibilities, styles and object-signs is a precondition for the condition. The study of materiality within the field of consumption owes its existence to this cultural logic of excess and the associated task of selection. In the end, the elementary problem is what to choose - for the objects one engages with acquire performative capacities - and, crucially, how to explain - to oneself or others - why one has chosen such a thing. As these data suggest, it is the process of explaining or accounting for personal selection within particular social contexts that permits the feeling of anxiety to surface. In constructing a narrative of taste that provides for 'performative fusion' (Alexander 2004a) between things and words, these enthusiastic consumers face various dilemmas that need to be resolved or rationalised - from what aspect of their home's colour scheme they don't like, to the appearance of particular objects of their living room, and the balance between maintaining a perceived 'authentic' identity that avoids the excesses of consumerist values, and one that is seen to engage too heavily with consumption, fashion and lifestyle.

Of course, questions need to be asked about the setting that allows these accounting behaviours to surface: the semi-structured interview. The most difficult question to assess is whether these data would exist outside the setting of this study. Put another way, are they in fact created within the interview setting? Furthermore, in this case, the specific question arises about whether these people actually became anxious about their aesthetic choices as a response to the interview setting. Though all care was taken by the interviewer to take a non-intimidating approach and to listen to and be directed by participant's talk about their domestic objects, I believe that the answer to this question is, surely, yes. The paradox of this methodological approach is that in order to study the expression of such anxieties, the researcher must play a role - however unwittingly - in provoking them. In the cases reported in this paper it was not a goal of the study to provoke such anxieties, but the result can be seen to resemble an experimental situation where the anxieties expressed were a direct result of the accounting talk required by, and generated within, the semi-structured research interview context. Put another way, these anxieties surfaced as a consequence of the accounting process which form the basis of the face-to-face, semistructured research interview. The data reported may be an artefact of the interview, but are they entirely unlikely to appear in other social settings where participants are required give an account of some aspect of their behaviour? Such discursive anxieties may be a more general response to 
certain social situations, rather than necessarily unnatural or contrived ${ }^{8}$, existing within this study's context only.

Though the semi-structured interview often resembles a friendly conversation more than a survey, to tour a virtual stranger around your house and its contents could provoke a response of anxiety in some people, even those one might consider consumer or aesthetic experts. Another way of considering the problem is to see this type of interview as merely another type of social setting or interaction where the narratives are constructed in situ: "understanding how the meaning-making process unfolds in the interview is as critical as apprehending what is substantively asked and conveyed” (Holstein and Gubrium, 1997:114). Such a position has been advocated in recent theories of the "active interview" (e.g. Briggs 1996, Holstein and Gubrium 1997, Miller and Glassner 1997, Denzin 2001) in the literature on qualitative research:

"Treating interviewing as a social encounter in which knowledge is constructed suggests the possibility that the interview is not merely a neutral conduit or source of distortion, but is instead a site of, and occasion for, producing reportable knowledge itself” (Holstein and Gubrium 1997:114)

If one accepts that a face-to-face interview such as the ones used in this research are fundamentally defined by being a social setting, then it is possible that these anxieties might also find expression in any other type of social setting, for example, when a group of friends come over for dinner, or when people drop in unannounced to an untidy house. In certain social situations then - for example when the audience is mostly unknown to them, in a novel social setting, or where a substantial difference in social status exists between those within a social setting - some people are prone to feel anxious about their possession and selections.

The larger question concerns the epidemiology of consumption anxiety. Of course, this paper cannot address such a matter as it is based on a small number of cases which have an illustrative and exploratory value. This caveat aside, anxiety is an important subject for consumption studies scholars. On the one hand, it may be that certain social fractions are more prone to experience anxiety as an element of their consumption style and that this is in fact one important element driving their high levels of ongoing discretionary, 'expressive' expenditure. Indeed, this paper draws upon extracts from seven interviews from a larger set of twenty-four interviewees. That such expressions of anxiety could not be identified in the remaining interviews may be taken as 
suggestive of such an hypothesis, yet the problem to consider is that in this case all respondents were from relatively homogeneous social backgrounds. Further support can be identified in Bourdieu's (1984) empirical study of modes of acquisitiveness in France. In it, Bourdieu vividly illustrates the possibility that anxieties afflict social fractions uniquely in his dissection of the consumption patterns of the petit bourgeoisie. Bourdieu points out that the fatal error in their relation to culture is to have a strong desire to know and acquire expert knowledges, rather than to recognise them as a product of learning. The petit bourgeoisie - one of Bourdieu's favourite objects of scorn - have an obsession with stockpiling cultural symbols, identify culture with mere knowledge, and adopt a strategy of over-earnest cultivation (1984:330-331). The petit bourgeoisie are thus caught in an "anxious quest for authorities and models of conduct” (Bourdieu 1984:331) whose fatal move is to combine avidity with anxiety (1984:323). Alternatively, it may be that certain anxieties underpin all consumption acts, irrespective of social class or background. That is, that acquisitiveness as a cultural practice may be associated with a form of anxiety - "the consuming desire of consuming” (Bauman 2001:13). The irony of a consumerist society is that it does not satisfy needs, but actually multiplies scarcities and as a result it also multiplies anxieties $^{9}$, through the stimulation of desire (Turner and Rojek 2002:34).

\section{Conclusion}

The data I have presented here must be seen as exploratory and contingent. Yet, they do make a preliminary empirical contribution to understanding consumption anxiety by specifying the existence of two types of anxiety. In doing so, the data also suggest that consumption anxiety is not just about aesthetic superiority and distinction, or what could be labeled 'status-based anxiety', but that managing consumption practice with reference to broader questions of social and self-identity can be a source of anxiety. This can be labeled 'identity-based' anxiety. So, it may be that there are different dimensions of social anxiety evident here, and the problem for these consumers in offering their accounts is that they need to find a happy balance between demonstrating competence within the realm of aesthetic consumption and a self-identity that is not perceived as too materialistic and shallow.

It is important to note that these data do not show that anxiety is always present for these consumers. Nor does it suggest that these anxieties are sources of deep psychological pain. Most likely they are not. In fact, it may be that some people garner some satisfaction from thinking about perceived aesthetic imperfections of inconsistencies, either as a form of leisure or as a type of identity play. Given the context of data collection, the conclusion I draw is that such anxieties 
are likely to be ephemeral and fleeting, and they are not ordinarily problematic or neurotic anxieties, but are in fact rationalised within social settings as a matter of interactional routine. They have a performative quality, being a result of social context and reflexive presentations of self in relation to commodity objects. Further talk-based studies which uncover actor-based narratives and accounts of consumption practice within particular domains such as fashion and clothing, home purchase and renovation, or car purchase is one way to proceed in developing models of the expression of narrativised consumption anxieties. In this way, to conceive consumption as a performative accomplishment, where actors draw upon narratives, codes and symbols to continuously enact their identity and give meaning to material possessions can advance consumption studies. To complement such studies of 'consumption performances', it would be unwise to rule out the use of nuanced survey approaches that allow measurement of general consumption practices, habits, values and attitudes, and their association with theoretical explanations of consumption. Each represents an important component in developing an adequate explanation of modern consumption. 


\section{Bibliography}

Alexander, Jeffrey C. (2004a) 'From the depths of despair: Performance, counterperformance, and “September 11”', Sociological Theory, 22(1): 88-105.

Alexander, Jeffrey C. (2004b) 'Cultural pragmatics: Social performance between ritual and strategy', Sociological Theory, 22(4): 527-573.

Austin, John L. (1962) How to Do Things with Words, $2^{\text {nd }}$ ed. Cambridge: Harvard University Press.

Barthes, Roland (1957[1993]) Mythologies, Trans. Lavers, Annette. London: Vintage.

Bataille, Georges (1985) Visions of Excess: Selected Writings, 1927-1939, Edited by Stoekl, Allan. Minneapolis: University of Minnesota Press.

Baudrillard, Jean (1968[1996]) The System of Objects, Trans. Benedict, J. London: Verso.

Bauman, Zygmunt (1987) Legislators and Interpreters. On Modernity, Postmodernity and Intellectuals, Cambridge: Polity Press.

Bauman, Zygmunt (1988) Freedom, Milton Keynes: Open University Press.

Bauman, Zygmunt (2001) ‘Consuming life’ Journal of Consumer Culture, 1(1): 9-29.

Beck, Ulrich (1992) Risk Society: Towards a New Modernity, London: Sage.

Blumer, Herbert (1969) 'Fashion: From class differentiation to collective selection', The Sociological Quarterly, 10: 275-291.

Bourdieu, Pierre (1984) Distinction. A Social Critique of the Judgement of Taste, London: Routledge.

Briggs, Charles (1986) Learning How to Ask: A Sociolinguistic Appraisal of the Role of the Interviewer in Social Science Research, Cambridge: Cambridge University Press. 
Butler, Judith (1997[1988]) 'Performative acts and gender constitution. An essay in phenomenology and feminist theory', in Conboy, K., Medina, N., and Stanbury, S. (1997) Writing on the Body. Female Embodiment and Feminist Theory, New York, Columbia University Press.

Campbell, Colin (1987) The Romantic Ethic and the Spirit of Modern Consumerism, Oxford: Basil Blackwell.

Campbell, Colin (1994) 'Consuming goods and the good of consuming', Critical Review, 8(4): 503-520.

Campbell, Colin (1995) 'Conspicuous confusion - A critique of Veblen’s theory of conspicuous consumption', Sociological Theory, 13(1): 37-47.

Denzin, Norman (2001) 'The reflexive interview and a performative social science', Qualitative Research, 1(1): 23-46.

Freud, Sigmund (1922) A General Introduction to Psychoanalysis, New York: Boni and Liveright.

Geertz, Clifford (1973) The Interpretation of Cultures, New York: Basic Books.

Giddens, Anthony (1991) Modernity and Self-Identity. Self and Society in the Late Modern Age, UK: Polity Press.

Goffman, Erving (1951) 'Symbols of Class Status’, British Journal of Sociology 2(4): 294-304.

Harré, Rom (2002) 'Material Objects in Social Worlds', Theory, Culture and Society, 19(5/6):2333.

Holstein, James A., and Gubrium, Jaber F. (1997) 'Active Interviewing', in Silverman, David (ed) Qualitative Research. Theory, Method and Practice, pp. 113-129. London: Sage Publications. 
Kierkegaard, Soren (1957) The Concept of Dread, Princeton: Princeton University Press.

Kopytoff, Igor (1986) 'The cultural biography of things: commoditization as process' In Appadurai, Arjun The Social Life of Things. Commodities in Cultural Perspective, Cambridge: Cambridge University Press.

Lamont, Michel (1992) Money, Morals and Manners. The Culture of the French and American Upper-Middle Class. Chicago: The University of Chicago Press.

Leary, Mark, R. (1983) Understanding Social Anxiety: Social, personality and clinical perspectives, Beverly Hills: Sage Publications.

May, Rollo (1950) The Meaning of Anxiety, New York: The Ronald Press Company.

Miller, Jody and Glassner, Barry (1997) 'The 'Inside' and the 'Outside'. Finding Realities in Interviews’ In Silverman, David (ed) Qualitative Research. Theory, Method and Practice, pp. 99112, London: Sage Publications.

Petersen, Richard (1992) 'Understanding audience segmentation: From elite and mass to omnivore and univore' Poetics, 23, 243-258.

Petersen, Richard and Kern, RM. (1996) 'Changing highbrow taste: From snob to omnivore' American Sociological Review, 61, 900-907.

Schechner, Richard (1993) The Future of Ritual. Writings on Culture and Performance, Routledge: London.

Shotter, John (1984) Social Accountability and Selfhood, New York: Basil Blackwell.

Simmel, Georg (1904[1957]) ‘Fashion’, The American Journal of Sociology LXII(6):541-58.

Speer, S. A., (2002) “'Natural' and 'contrived' data: a sustainable distinction?”, Discourse and Society, 4(4): 511-525. 
Taylor, C.B., and Arnow, B. (1988) The nature and treatment of anxiety disorders, New York: Free Press.

Turner, Bryan S., and Rojek, Chris (2002) Society and Culture. Principles of Scarcity and Solidarity, London: Sage.

Turner, Victor (1982) From Ritual to Theatre. The Human Seriousness of Play, New York: Performing Arts Journal Publications.

Vandenberghe, Frédéric (2002) 'Reconstructing Humants: A Humanist Critique of ActorNetwork Theory', Theory, Culture and Society 19(5/6): 51-67.

Veblen, Thorstein (1899[1934]) The Theory of the Leisure Class: An Economic Study of Institutions, New York: Modern Library.

Warde, Alan (1994) 'Consumption, Identity-Formation and Uncertainty’, Sociology 28(4): 877898.

Warde, Alan (1996) ‘Afterword: The future of the sociology of consumption’ In, Edgell, Stephen, Hetherington, Kevin, and Warde, Alan. Consumption Matters. The Production and Experience of Consumption, Oxford: Blackwell Publishers/The Sociological Review.

Warde, Alan (1997) Consumption, Food and Taste, London: Sage.

Wilkinson, Iain (1999) 'Where is the Novelty in our Current 'Age of Anxiety'? European Journal of Social Theory 2(4): 445-467.

Woodward, Ian (2004) 'Divergent Narratives in the Imagining of the Home Amongst MiddleClass Consumers: Aesthetics, Comfort and the Symbolic Boundaries of Self and Home', Journal of Sociology, 39(4): 391-412. 


\section{Acknowledgements}

My gratitude goes to Michael Emmison and Philip Smith for their generous assistance throughout this project, and to the development of this paper. Thank you also to Bruce Buchan for comments on an earlier version of the paper. My appreciation goes to Yale University's Center for Cultural Sociology, and participants in the Center's workshop series, who enthusiastically gave many thoughtful and stimulating comments on an earlier version of this paper. Here I must especially thank Jeffrey Alexander, Ron Eyerman, Jason Mast, Isaac Reed, Martin de Santos, and Michael Yarbrough for comments that prompted me to fine-tune parts of the paper. I would also like to thank Kay Ferres and Wayne Hudson for generous assistance that allowed me to visit the Yale University Center for Cultural Sociology in early 2005.

\section{Notes}

\footnotetext{
${ }^{1}$ For the purpose of this paper, one can understand aesthetic consumption to mean any type of consumption where user notions of 'beauty' and 'good' are major elements of the consumption act. I make this distinction realising that to distinguish between consumption that is 'non-aesthetic' (or 'utilitarian') and that which is 'aesthetic' (or 'expressive') is often useful only in theory: frequently most consumption acts contain both dimensions.

${ }^{2}$ For example, contemporary research on the practices of omnivorous consumption which have modified some of Bourdieu's findings outside the French context. See Petersen (1992) and Petersen and Kern (1996).

${ }^{3}$ For example, see Lamont's (1992) study of how everyday categories of 'like/not like me' influence attitudes and social affiliations. Lamont shows how the use of such category distinctions draw the symbolic boundaries of one's taste, and constitute the process by which actors (unequally) categorize objects, people and practices.

${ }^{4}$ In contrast to questions of consumption and class, status and cultural inequality, relatively little empirical scholarly inquiry has been directed toward understanding the interpretive and performance based components of the consumption act. I want to stress that it is not the purpose of this paper to challenge the foundational notion that consumption acts can be about social difference, or that they often do 'social work' relating to cultural inclusion and exclusion. Rather, by applying the concept of 'consumption anxiety' to data collected as part of a larger project on the narrativisation of aesthetic choice in relation to consumption in the home, the paper explores the way social pressures of consumption and aesthetic selection are dealt with at an individual level as part of accomplishing a 'culturally warrantable' (Denzin 1989:77) and accountable (Shotter 1984) narrative of selection. In short, the paper considers how object things enter in to the social world and acquire a performative capacity through narrativisation (Harré 2002, Vandenberghe 2002): it is about the accomplishment of a relation between 'words' and 'things' (Austin 1962).

${ }^{5}$ In a reflection on the state of consumption studies and questions of method and measurement published elsewhere, Warde (1996) argues that consumption might best be seen as contextual, sequential and frequently inconsistent. In fact - consistent with the ambition of this paper - he suggests that "consumption practices comprise a perpetual series of short performative episodes" (1996:308), and calls for ethnographic attention to the need to understand the different social worlds that consumption occurs in.

${ }^{6}$ Commonly used psychological instruments include the Hamilton Anxiety Rating Scale, The Stanford Panic Appraisal Inventory, Common Fears and Phobias Questionnaire, and the Social Anxiousness Scale. See Taylor and Arnow (1988) and Leary (1983) for further details.

${ }^{7}$ For a full discussion of the findings of this larger study, see Woodward 2004.

8 See Speer (2002) for a useful discussion and synthesis of these debates.

${ }^{9}$ As the paper argues, these anxieties can be identified in the discursive 'toing and froing' of expressions of uncertainty, evident in the way people weigh up their choices in terms of questions of aesthetics and identity.
} 